\title{
A Molecular Beacon Approach to Measuring the DNA Permeability of Thin Films
}

\author{
Angus P. R. Johnston and Frank Caruso* \\ Centre for Nanoscience and Nanotechnology, Department of Chemical and Biomolecular Engineering, \\ The University of Melbourne, Victoria 3010, Australia.
}

\section{Supporting Information}

Materials. Poly(ethyleneimine) (PEI, $\mathrm{M}_{\mathrm{w}}=25000 \mathrm{~g} \mathrm{~mol}^{-1}$ ), poly(styrenesulfonate) (PSS, $\mathrm{M}_{\mathrm{w}}=70000 \mathrm{~g} \mathrm{~mol}^{-1}$ ), poly(allylamine) hydrochloride $\left(\mathrm{PAH}, \mathrm{M}_{\mathrm{w}}=70000 \mathrm{~g} \mathrm{~mol}^{-1}\right)$, corn recombinant avidin, fluorescein-biotin, 1ethyl-3-(3-dimethylaminopropyl)carbodiimide hydrochloride (EDC), N-hydroxysuccinimide (NHS), sodium chloride, and sodium citrate were obtained from Sigma-Aldrich and used as received. Target oligonucleotides (See Table 1) were custom synthesized by Geneworks (Adelaide, South Australia). The molecular beacon (MB) was custom synthesized by TriLink BioTechnologies (San Diego, USA) with a 5' Cy3 modification, a 3' Black Hole Quencher 2 (BHQ2) modification and a biotin-modified thymidine residue at the first nucleotide on the 5' end. High purity water (Milli-Q) with a resistivity greater than $18 \mathrm{M} \Omega \mathrm{cm}$ was obtained from an inline Millipore RiOs / Origin system. $100 \mathrm{~mL}$ of SSC buffer containing $500 \mathrm{mM} \mathrm{NaCl}$ and $50 \mathrm{mM}$ citrate was made with $4.8 \mathrm{~g}$ of citric acid and $14.6 \mathrm{~g}$ of $\mathrm{NaCl}$. The $\mathrm{pH}$ of the buffer solution was measured with a Mettler-Toledo MP220 pH meter and adjusted to $\mathrm{pH} 6.5$ using $1 \mathrm{M}$ sodium hydroxide.

Table 1 - DNA Sequences ${ }^{\mathrm{a}}$

\begin{tabular}{|c|c|}
\hline Name & Sequence \\
\hline Target15 & 5' GCTGAATGAGATGGA 3' \\
\hline Target 25 & 5' GCTACGCTGAATGAGATGGACGCAA 3' \\
\hline Target35 & 5' GTAATGCTACGCTGAATGAGATGGACGCAAGCTCC 3' \\
\hline Target60 & 5' GTGCCACAGGAAGTAATGCTACGCTGAATGAGATGGACGCAAGCTCCCCTCGCTGCTGGG 3' \\
\hline MB & 5' (Cy3) (Biotin dT) GCTCGTCCATCTCATTCAGCCGAGCA (BHQ2) 3' \\
\hline
\end{tabular}

${ }^{\mathrm{a}}$ The bold sequences correspond to the probe and complementary target of the $\mathrm{MB}$ and the underlined sequences correspond to the stem of the MB.

Methods. Avidin Functionalization: Avidin was covalently attached to the amine-functionalized BMS particles using EDC/NHS coupling chemistry (Walsh, M.K.; Wang, X.; Weimer, B.C. J. Biochem. Bioph. Meth. 2001, 47, 221). Amine-functionalized BMS particles (Wang, Y.; Caruso, F. Chem. Commun. 2004, 1528) (1 mg) were suspended in $50 \mu \mathrm{L}$ of Milli-Q water and $25 \mu \mathrm{L}$ of a $1 \mathrm{mg} \mathrm{mL}^{-1}$ solution of avidin was added to the solution. 20 $\mu \mathrm{L}$ of freshly made solutions of EDC $\left(100 \mathrm{mg} \mathrm{mL}^{-1}\right)$ and NHS $\left(20 \mathrm{mg} \mathrm{mL}^{-1}\right)$ were added to the particles and allowed to react at room temperature for $4 \mathrm{~h}$ with gentle agitation. The particles were washed thoroughly in Milli-Q water before storage in a $50 \mathrm{mM}$ citrate/500 $\mathrm{mM} \mathrm{NaCl}$ buffer.

Biotin Attachment: Fluorescein-modified biotin was attached to the avidin-modified BMS particles by adding 5 $\mu \mathrm{L}$ of a $5 \mu \mathrm{M}$ solution of the biotin solution to $50 \mu \mathrm{L}$ of the particles. The uniform fluorescence of the particles (Figure 1) shows that avidin was distributed evenly throughout the particles. The biotin-modified MB was attached to the avidin-modified BMS particles by adding $5 \mu \mathrm{L}$ of a $5 \mu \mathrm{M}$ solution of the MB to $50 \mu \mathrm{L}$ of the avidin-modified particles. The MB was designed with a $15 \mathrm{~b}$ loop structure and a $6 \mathrm{~b}$ stem, with Cy3 coupled to the 5' end and BHQ2 coupled to the 3' end. A biotin-modified thymidine residue was incorporated into the 5' end of the stem to allow attachment of the MB inside the BMS particles. After 10 min the particles were thoroughly washed in the citrate buffer. 


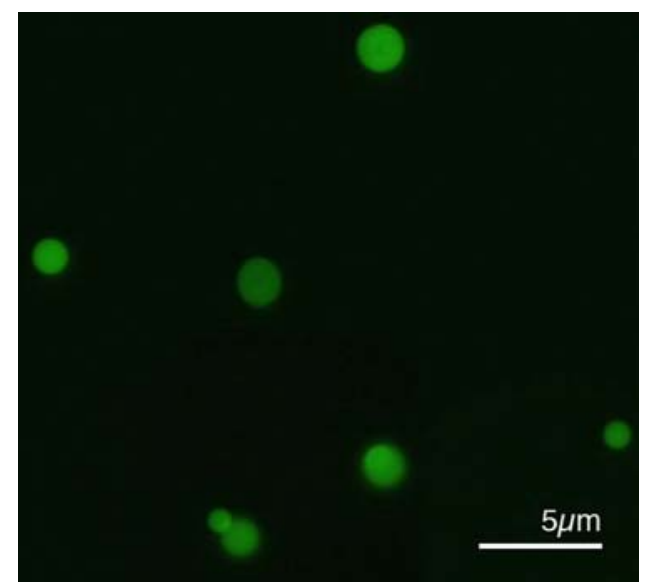

Figure 1. Avidin-functionalized BMS particles modified with fluorescein-biotin.

Layer-by-Layer (LbL) Assembly: LbL coating of the BMS particles was performed as outlined elsewhere (Caruso, F.; Caruso, R. A.; Möhwald, H. Science 1998, 282, 1111). Briefly, the particles were alternately suspended in a positive polyelectrolyte solution (PAH, $1 \mathrm{mg} \mathrm{mL}^{-1}$ in $500 \mathrm{mM} \mathrm{NaCl}$ ) and negative polyelectrolyte (PSS, $1 \mathrm{mg} \mathrm{mL}^{-1}$ in $500 \mathrm{mM} \mathrm{NaCl}$ ). After each deposition of polyelectrolyte, the particles were washed in 500 $\mathrm{mM} \mathrm{NaCl}$ solution to remove any loosely bound polyelectrolyte. A layer of fluorescein-labeled PAH was deposited as the third layer on the film to confirm deposition of the polyelectrolytes occurs predominantly on the surface of the particles. Confocal microscopy showed a ring of fluorescence on the surface of the particles (Figure 2).

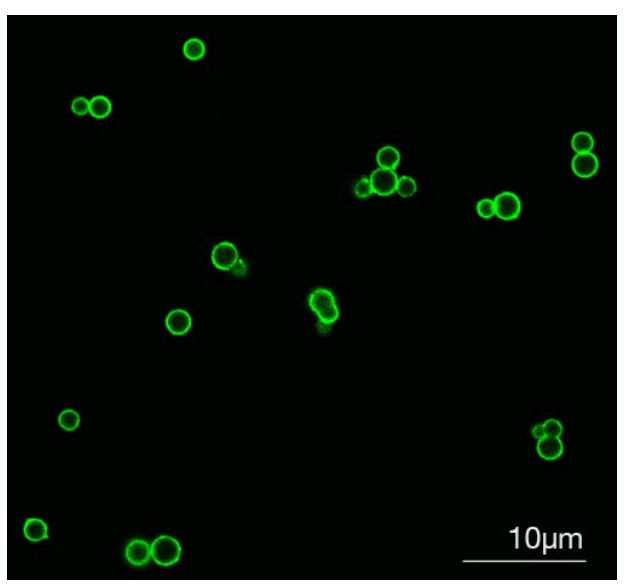

Figure 2. MB/BMS particles coated with PEI/PSS and fluorescein-labeled PAH.

Fluorescence Spectroscopy: Fluorescence spectroscopy was performed by adding $1 \mu \mathrm{L}$ of $150 \mu \mathrm{M}$ MB solution to $2 \mathrm{~mL}$ of SSC buffer. $10 \mu \mathrm{L}$ of a $10 \mu \mathrm{M}$ target DNA solution was added to the MB solution and incubated at $20{ }^{\circ} \mathrm{C}$ for $1 \mathrm{~h}$. The MB was excited at $540 \mathrm{~nm}$ and the spectrum acquired from $550-650 \mathrm{~nm}$. The emission intensity was measured and the emission maxima $(565 \mathrm{~nm})$. Spectra were also acquired in the presence of $0.5 \mathrm{mg}$ $\mathrm{mL}^{-1} \mathrm{PEI}$, and no significant difference in the emission intensity was observed, suggesting the PEI does not open the $\mathrm{MB}$, nor prevent the MB from opening.

DNA Permeation: $10 \mu \mathrm{L}$ of MB particles (uncoated or LbL coated) were added to $50 \mu \mathrm{L}$ of SSC buffer. $5 \mu \mathrm{L}$ of a $5 \mu \mathrm{M}$ solution of the various length DNA targets was added to the solution. To avoid secondary structures that could affect the permeability through the film, the sequences were designed so there was minimal selfcomplementarity. The particles were incubated with the targets for 3, 75 and $500 \mathrm{~h}$. The fluorescence of the particles was measured using flow cytometry.

Flow Cytometry: Fluorescence measurements of the particles were made using a Becton Dickinson FACS Calibur flow cytometer. The incubated particle solution was diluted with $200 \mu \mathrm{L}$ of SSC buffer and $200 \mu \mathrm{L}$ of this solution was analyzed on the instrument. Measurements were acquired with triggering on the forward scatter detection (E0 detector) with a threshold of 400. Cy3 fluorescence was monitored on the FL2 parameter with a 
PMT voltage of $650 \mathrm{~V}$. For each target DNA, 25,000 particles were analyzed at a rate of approximately 500 particles per second. For each incubation time, a background sample was recorded (i.e., particles exposed to the same assembly and incubation conditions, but with no target DNA added). This signal was subtracted from the signal of the particles incubated with the different targets. The molecular equivalents of fluorochrome were calibrated from the fluorescence signal (in arbitrary units) from 8 peak Rainbow calibration particles (Spherotech), which contained known numbers of fluorochrome in each particle.

DNA Size. The size of the single stranded (ss) DNA molecules can be estimated using the Kratky-Porod equation (Kopecka, K.; Drouin, G.; Slater, G. W. Electrophoresis, 2004, 25, 2177-2185):

$$
R_{g}^{2}=\frac{p L_{D}}{3} \times\left[1-3\left(\frac{p}{L_{D}}\right)+6\left(\frac{p}{L_{D}}\right)^{2}-6\left(\frac{p}{L_{D}}\right)^{3} \times\left(1-e^{-\frac{L_{D}}{p}}\right)\right]
$$

where $R_{\mathrm{g}}$ is the radius of gyration, $p$ is the persistence distance of the oligomer and $L_{\mathrm{D}}$ is the length of the oligomer. For ssDNA, the contribution to the length for each base is approximately $0.43 \mathrm{~nm}$. ssDNA is a very flexible molecule, with a persistence distance of around 3 bases. Table 2 summarizes the sizes of the targets used.

Table 2 - DNA size estimated using the Kratky-Porod equation

\begin{tabular}{|c|c|c|c|c|}
\hline Sequence & Length (bases) & Length $(\mathrm{nm})$ & Radius of Gyration $(\mathrm{nm})$ & Diameter $(\mathrm{nm})$ \\
\hline Target15 & 15 & 6.5 & 1.5 & 3.1 \\
\hline Target25 & 25 & 10.8 & 2.3 & 4.7 \\
\hline Target35 & 35 & 15.1 & 3.0 & 6.0 \\
\hline Target60 & 60 & 25.8 & 4.3 & 8.6 \\
\hline
\end{tabular}

